\title{
Um estudo com egressos de instituições para crianças em situação de rua: percepção acerca da situação atual de vida e do atendimento recebido
}

\author{
Normanda Araújo de Morais \\ Universidade de Fortaleza \\ Silvia Helena Koller \\ Universidade Federal do Rio Grande do Sul
}

\begin{abstract}
Resumo
Este artigo objetiva identificar a situação atual de vida de egressos de uma instituição de atendimento para crianças e adolescentes em situação de rua, a avaliação que fazem do momento atual de vida, bem como compreender a sua percepção acerca da referida instituição e do atendimento recebido. Participaram nove adolescentes do sexo masculino (18-20 anos). Utilizou-se uma entrevista semi-estruturada, a qual foi analisada a partir do procedimento de análise de conteúdo. Os resultados mostraram uma variedade de situações de vida. O momento atual de vida foi descrito como satisfatório e a instituição frequentada no passado também foi avaliada de forma positiva. Os resultados são discutidos à luz da trajetória de vinculação institucional (TVI), das modalidades de saída da rua descritas na literatura e da importância da vinculação educador criança/adolescente. Implicações para as políticas públicas de atendimento a essa população são discutidas.

Palavras-chave: situação de rua; adolescentes; instituição; avaliação.
\end{abstract}

\begin{abstract}
A study on street children who have left institutions: perceptions of current life situations and received treatment. This article aims to identify the life situations of street children and adolescents after leaving care institutions; note how they evaluate their current life; and understand how they perceive the institution in which they stayed and the treatment they received there. Nine male adolescents participated (18-20 years old). A semi-structured interview script, evaluated through content analysis, was used. The results revealed a variety of life situations. The participants tended to describe their current life situation as satisfactory and they also positively evaluated the institution in which they stayed. The results are discussed in the context of Institutional Tie Trajectory (ITT); the modalities for leaving the streets as described in the literature; and the importance of the relationship between educator and child/adolescent. The implications for public policies treating this population are discussed.
\end{abstract}

Keywords: street situation; adolescents; institution; evaluation.

$\mathrm{A}$ literatura sobre o desenvolvimento de crianças em situação de rua apresenta um grande volume de estudos descritivos acerca das condições de vida dessa população (quem são, como vivem, quais as estratégias de sobrevivência utilizadas na rua, motivações para a saída de casa, dentre outros). Além disso, há um volume considerável e em franca expansão de estudos acerca do envolvimento dessas crianças e adolescentes com comportamentos de risco para a sua vida e saúde - drogas, comportamento sexual de risco, suicídio, violência, etc. (Morais, Neiva-Silva, \& Koller, 2010; Raffaelli, 1999; Raffaelli, Koller, \& Morais, 2007).

Em contrapartida, estudos sobre o papel das instituições de atendimento na vida dessas crianças e adolescentes que se encontram em situação de rua são bem mais escassos, praticamente inexistem. Tal característica tem aberto uma demanda crescente por estudos que visem a avaliar o atendimento ofertado, assim como o impacto que esses serviços geram na vida de crianças/adolescentes em situação de rua a curto e longo prazo. Acredita-se que a realização de estudos desse tipo é fundamental para avaliar e (re) definir perspectivas de atendimento mais adequadas à população infanto-juvenil em situação de rua (Harris, Johnson, Young, \& Edwards, 2011; Milburn, Rosenthal, \& Rotheram-Borus, 2005; Ramos, 2006; Westphal, 2001).

Em outra dimensão, constata-se igual escassez de estudos que identifiquem a situação atual de vida de crianças/ adolescentes que tiveram algum tipo de vínculo com a rua (moradia ou trabalho, por exemplo) no passado. Nesse sentido, 
onde estariam e como viveriam crianças/adolescentes em situação de rua que foram atendidos por uma instituição no ano de 2002? Onde poderíamos achá-las e como estariam vivendo sete anos depois? Que avaliação elas poderiam fazer do atendimento recebido em uma instituição de meio aberto ${ }^{1}$ que frequentavam quando estavam nas ruas?

\section{Trajetórias de crianças e adolescentes em situação de rua: o papel das instituições e a "saída da rua"}

A fim de compreender as trajetórias de vida de crianças/ adolescentes em situação de rua, um aspecto é essencial: o perfil - heterogêneo - de vinculação dos mesmos com a rua (Morais et al., 2010). Esse perfil pode envolver a vinculação com a rua em diferentes modalidades: trabalho, moradia e lazer, por exemplo, as quais podem estar juntas ou separadas na vida de cada criança/adolescente. Por outro lado, a situação de rua pode ser esporádica/temporária para alguns; tornar-se crônica para outros por um período de tempo; ou mesmo uma "forma de vida” para algumas crianças/adolescentes (Milburn et al., 2005).

A trajetória é um elemento central que define o lugar que a criança/adolescente ocupa na rua. Esse lugar difere quase sempre de um indivíduo para outro em função da etapa na qual se encontra, assim como das etapas que já percorreu. Cada etapa é percorrida de forma diferente e em ritmos também diferentes pelos indivíduos (Lucchini, 2003). Uma criança pode, por exemplo, parar em uma determinada etapa ou "queimar" uma delas. O conhecimento da etapa na qual a criança/adolescente se encontra e de sua trajetória é indispensável para qualquer intervenção que visa a melhorar a situação da criança enquanto ela está na rua, ou afastá-la desse espaço. A ideia, portanto, é a de que a intervenção seja adequada ao momento de vida em que se encontra a criança/adolescente em situação de rua (Santana, Doninelli, \& Koller, 2010). Ademais, alguns autores (por exemplo, Milburn et al., 2005) afirmam que - quanto antes essa trajetória de vinculação com a rua possa ser rompida, tanto mais interessante e eficaz.

De acordo com Lucchini (2003), as etapas da trajetória de vida de uma criança ou adolescente em situação de rua são produzidas por diferentes fatores, os quais explicam a diversidade das trajetórias pessoais. Dentre os fatores estão: a) modalidades de partida para a rua; b) referências e modelos identitários; c) competências simbólicas e instrumentais; d) grau de inserção e participação na vida da rua; e) movimentos entre os diferentes campos (rua, família, parentes, escola, instituição, etc.); f) necessidades e motivações; g) modalidades de saída da rua; e h) experiências institucionais (ONG, polícia, justiça, mídia, sistema educativo, emprego).

Especificamente sobre as modalidades de saída da rua, temática de interesse do presente artigo, Lucchini (2003) descreve três formas: a) saída ativa - ligada a uma escolha e à elaboração de um projeto concreto de vida; b) saída por expulsão ou deslocamento forçado - ocorre nos casos de prisão ou institucionalização prolongada; e c) saída por esgotamento de recursos - difere da saída ativa, pois a criança/adolescente não tem projeto nem alternativa real para a rua. Quase sempre, nesses casos, a alternativa é a volta para a casa, o que torna esse tipo de saída muito instável, já que envolve numerosos retornos à rua.

Santana et al. (2010) propuseram o conceito de Trajetória de Vinculação Institucional (TVI) para compreender a relação que as crianças/adolescentes em situação de rua estabelecem com as instituições de atendimento, com suas famílias e com a própria rua. As autoras usaram a expressão "vinculação institucional", pois o seu foco de interesse era a relação estabelecida por crianças/adolescentes em situação de rua com as instituições destinadas ao atendimento dessa população na cidade de Porto Alegre, RS. As instituições costumavam atender crianças/ adolescentes que possuíam uma vinculação de moradia com a rua e não apenas de sobrevivência, e que possuíam vínculos familiares bastante fragilizados. Segundo as autoras, a TVI está dividida em quatro etapas:

1) A primeira etapa da TVI consiste em uma não-vinculação institucional. Em geral, nessa fase, as crianças/adolescentes utilizam a rua para brincadeiras e passeios e para a obtenção de dinheiro (mendicância ou venda de produtos), a fim de complementar a renda familiar. Para essas crianças/adolescentes, a família é a principal fonte de referência, sendo que a maioria ainda mora com os familiares. Além disso, frequentam, de uma maneira geral, escolas formais, localizadas em seus bairros de origem.

2) A segunda etapa da TVI caracteriza-se pela intermitência das relações da criança/adolescente com as instituições, a rua e a família. Nessa etapa há grandes transformações na relação da criança/adolescente com a rua, havendo o primeiro contato com as instituições de atendimento à população infanto-juvenil em situação de rua. O jovem ainda possui como ponto de referência principal a família, mas a rua e a instituição são cada vez mais presentes em sua rotina.

3) A terceira etapa refere-se ao período de maior contato do adolescente com as instituições de atendimento. Nesse momento da trajetória, o adolescente tem na rua seu local de moradia, sendo que as opções institucionais se multiplicam, uma vez que esses jovens passam a ser reconhecidos enquanto público-alvo desses serviços. Em muitos casos, a relação com a família torna-se esporádica, sendo a rua e as instituições os principais locais para moradia, obtenção de alimentos, vestimentas e entretenimento. Apesar de essa etapa ser aquela em que há um maior contato entre as instituições e os adolescentes, esses tendem a utilizar-se dos serviços sem almejarem uma efetiva saída do espaço da rua.

4) Por fim, tem-se a quarta etapa da TVI, que se refere ao período em que o jovem está próximo de completar 18 anos, idade limite a qual os programas disponíveis atendem. Assim, conforme o adolescente vai aproximando-se dessa idade, cresce a tensão na relação do jovem com esses locais, sobretudo pela iminência de uma desvinculação. A tensão é agravada, tanto pela escassez de instituições que poderiam servir-lhe de apoio após essa idade, como pelo fato de que ter dezoito anos significa ser penalizado pelos atos infracionais cometidos. Nessa fase, ainda, muitos adolescentes desistem das instituições quando percebem que não conseguirão realizar o projeto de vida desenhado pela instituição. Eles preferem, então, abandonar a instituição antes que esta os abandone.

As quatro etapas anteriormente descritas são bastante 
úteis pra compreender a trajetória de crianças/adolescentes em situação de rua. No entanto, as crianças/adolescentes em situação de rua percorrem em ritmos e de forma diferente as etapas dessa trajetória (Santana et al., 2010). A ideia de trajetória, portanto, não implica dizer que ela passará pelas quatro etapas, uma vez que essas trajetórias também podem ser "rompidas", em favor de circunstâncias de vida mais protetivas para essas crianças/ adolescentes em situação de rua.

Dada a variedade de perfis de crianças e adolescentes em situação de vulnerabilidade social, é preciso que diferentes aparatos de acolhida e atenção a essa população sejam criados. Dentre esses programas, citam-se aqueles anteriores à vinda para a rua e aqueles que visam a resguardar o bem-estar e a qualidade de vida de crianças/adolescentes que já estão na rua (Morais, 2009).

Dentre as estratégias de atendimento anteriores à vinda para a rua, destaca-se a iniciativa de ONGs (em parceria com o poder público) que atendem crianças e adolescentes em situação de vulnerabilidade social, através de programas como o SASE (Serviço de Apoio Sócio-Educativo) e o Trabalho Educativo (Guareschi, Reis, Huning, \& Bertuzzi, 2007; Malvasi, 2008). Serviços como esse são oferecidos com o objetivo de garantir o desenvolvimento de habilidades e competências de crianças e adolescentes, através da sua inserção em um espaço protegido; e, a partir de formas de inserção social positiva (música, dança, esporte, etc.), evitar o envolvimento dessas crianças e adolescentes com o uso de drogas, comportamento sexual de risco, delinquência e com a situação de rua. Muitos desses serviços têm incorporado, cada vez mais ao seu trabalho, o trabalho com as famílias das crianças/adolescentes atendidos. Isso é feito através do estudo da situação familiar, da realização de grupos de pais/mães ou responsáveis e de encaminhamentos diversos (atendimento psicoterápico, outros atendimentos de saúde, situação previdenciária, empregos etc.).

No contexto da rua, porém, outras estratégias de atendimento devem estar disponíveis. Entre essas estratégias, destacam-se aquelas que preveem a provisão de recursos de sobrevivência (higiene, alimentação, sono, vestimenta e cuidados com a saúde, por exemplo), assim como o acompanhamento do caso de cada adolescente a partir das suas particularidades (internação para tratamento de dependência química, abrigamento, reinserção familiar, encaminhamento para estágios e programas de trabalho aprendiz, acompanhamento de cumprimento de medida socioeducativa, etc.). Também nesses serviços, deve haver a preocupação pela situação familiar das crianças/adolescentes atendidos. Diferentes serviços têm se configurado com esse objetivo, dentre os quais merecem destaque os abrigos diurnos, as escolas abertas, os albergues noturnos e os serviços de saúde específicos para o atendimento de crianças e adolescentes em situação de rua ${ }^{2}$.

Outra perspectiva que deve ser enfatizada para o atendimento de crianças/adolescentes em situação de rua é a abordagem feita nas ruas por educadores sociais, que compõem a chamada Educação Social de Rua (ESR). A ESR é um sistema políticopedagógico desenvolvido no Brasil no final da década de 1970, que teve como fontes inspiradoras a pedagogia de Paulo Freire, Celestine Freinet e Emília Ferreiro. Ela buscava lidar com o fenômeno dos "meninos de rua" em uma perspectiva não assistencialista, mas de forma que essas crianças/adolescentes pudessem elaborar, construir e controlar seus projetos de vida (Oliveira, 2004). De acordo com esse autor, a educação social de rua está baseada na "pedagogia da presença", segundo a qual é papel do educador ir ao encontro da necessidade da criança/ adolescente onde estes estiverem (praças, canteiros, bares, pontes, vilas etc.). Nessa pedagogia, por sua vez, tem lugar de destaque a vinculação que o educador e a criança/adolescentes constroem.

Vários estudos têm mostrado a relevância das instituições (nas suas diferentes configurações) para o atendimento às crianças e adolescentes em situação de vulnerabilidade social, incluindo a situação de rua. Tais estudos salientam que tanto o funcionamento da instituição quanto seus funcionários desempenham um importante papel na rede de apoio social e afetiva dos atendidos (Brito \& Koller, 1999; Santana, Doninnelli, Frosi, \& Koller, 2004; Siqueira, Betts, \& Dell'Aglio, 2006). Além disso, enfatiza-se aqui que mais do que simplesmente falar da modalidade de atendimento, o mais importante é conhecer a qualidade desse atendimento, sobretudo a qualidade das relações estabelecidas entre os educadores e os jovens atendidos (Morais, 2009; Morais, Koller, \& Raffaelli, 2012).

Westphal (2001) realizou uma pesquisa sobre a história de vida de 10 jovens entre 18 e 21 anos que viveram em situação de rua, cometeram atos infracionais e, a partir da intervenção socioeducativa, mudaram o comportamento de risco apresentado na adolescência. Para os jovens entrevistados, o fator mais relevante na decisão de sair da rua foi a oportunidade de ter sido ajudado por alguém. Essa ajuda, por sua vez, estava relacionada à oportunidade concreta de interações positivas que desenvolveram com os técnicos das instituições. Interações que foram marcadas pelo acolhimento afetivo, reconhecimento de potencialidades, valorização, apoio, oferta, alternativas prazerosa de ocupação (como o circo, por exemplo) e lazer e, sobretudo, a disponibilidade de escuta. A pesquisadora afirmou, ainda, que a realidade de vida pós-rua destes adolescentes continuava marcada por dificuldades (moradia e trabalho incertos, por exemplo). No entanto, o enriquecimento da rede social propiciado pela interação com as instituições funcionava como o principal suporte da reabilitação psicossocial.

Em outro estudo realizado por Pereira (2004) com 08 jovens egressos de uma instituição para crianças/adolescentes na cidade de Salvador, BA, o autor concluiu que os serviços oferecidos não foram capazes de modificar concretamente a vida material dos jovens atendidos e de suas famílias. Estes jovens, após deixarem a instituição, continuavam à margem do mercado de trabalho, encontrando-se desempregados e/ou exercendo trabalhos informais e precarizados (ambulantes, "bicos" na construção civil, por exemplo). Com base nesses dados, o referido autor problematiza a função social das instituições, questionando o papel reprodutivista/compensatório das mesmas e a dificuldade em atuarem numa perspectiva mais emancipatória.

Com base nas considerações acima acerca do papel das instituições na vida de crianças/adolescentes em situação de rua, bem como da necessidade de estudos que verifiquem o que aconteceu com crianças/adolescentes que um dia estiveram nas 
ruas, esse trabalho delineia o seu objetivo. Interessa, portanto, verificar a situação atual de vida de crianças que frequentaram um serviço de meio aberto (abrigo diurno) na cidade de Porto Alegre no ano de 2002, a avaliação que fazem da mesma, bem como a percepção que possuem acerca do papel que aquele serviço teve na sua vida.

\section{Método}

\section{Participantes}

Participaram do estudo nove jovens, todos do sexo masculino. A idade dos participantes variou entre 18-20 anos de idade $(M=19,2)$. Dos nove participantes da pesquisa, dois afirmaram continuar a viver na rua, dois em casa de parentes/ amigos ou familiares, dois em uma República e dois em um presídio da capital gaúcha. Um adolescente afirmou estar morando em uma casa sozinho (Tabela 1).

\section{Instrumento}

Utilizou-se um roteiro de entrevista especialmente elaborado para esse estudo, o qual continha questões abertas e de múltipla escolha. O roteiro estava dividido em nove partes. Destas, apenas duas serão analisadas no presente artigo: 1) caracterização e avaliação da situação atual de vida; e 2) percepção sobre a instituição de meio aberto e sobre o atendimento recebido.

\section{Procedimentos de coleta e análise de dados}

Todos os entrevistados tinham em comum o fato de terem frequentado uma instituição de meio aberto para crianças em situação de rua, localizada na cidade de Porto Alegre, RS, durante o ano de $2002^{3}$. Chegou-se até os seus nomes a partir de um levantamento nas folhas de frequência (de todos os meses de 2002) da referida instituição.

Nesse levantamento inicial, foi verificado que 142 crianças/ adolescentes diferentes acessaram em algum momento aquele serviço ao longo do ano de 2002. A seguir, contatou-se três educadoras da rede de assistência às crianças e adolescentes em situação de rua de Porto Alegre, funcionárias de serviços da rede de atendimento (Escola Aberta, Serviço de Acolhimento Noturno e Abrigo Diurno). O objetivo era que cada uma delas pudesse preencher uma lista, onde constavam todos os 142 nomes, dizendo se sabiam os locais prováveis de localização desses adolescentes.

A partir do cruzamento das três listas, teve início o processo de contatar os jovens egressos. Optou-se por privilegiar aqueles que ainda estavam frequentando algum serviço da rede de atendimento para jovens em situação de rua, que ficavam na rua em locais bastante conhecidos (como a rodoviária, por exemplo) e que estavam presos no mesmo presídio, por exemplo. Mesmo utilizando-se esse critério de facilidade de acesso, conseguiu-se entrevistar jovens em diferentes situações de vida (jovens que continuavam a viver na rua, que estavam morando com parentes ou amigos, que estavam morando sozinhos, frequentando uma República e que estavam presos). A República foi um serviço criado na época para atender jovens em situação de rua, recémegressos dos serviços de atendimento destinados a crianças e adolescentes, que haviam completado 18 anos. Tratava-se de uma casa onde os adolescentes podiam morar, estando com emprego ou em fase de procura. Lá contavam com a tutela de um educador e acompanhamento da rede de assistência social.

As entrevistas foram realizadas por uma psicóloga e, em alguns casos, por esta e uma auxiliar de pesquisa (estudante da Graduação do curso de Psicologia). As entrevistas duraram em média 45 minutos e foram feitas com o entrevistador anotando as respostas do participante.

Antes da realização das entrevistas, os participantes receberam as explicações sobre o propósito da pesquisa e a garantia acerca do sigilo de sua identidade. Somente após mostrarem-se de acordo e terem suas dúvidas esclarecidas é que foram entrevistados. Todos assinaram o termo de consentimento livre e esclarecido.

A análise de dados teve por base a Análise de Conteúdo de Bardin (1977/1979), realizada através do levantamento de categorias temáticas para cada resposta, as quais não foram definidas a priori. Utilizou-se, ainda, estatísticas descritivas (frequência e porcentagem), sempre que se julgou necessário a uma melhor visualização dos resultados.

\section{Resultados}

\section{Caracterização e avaliação da atual situação de vida}

A Tabela 1 apresenta a situação de vida de cada adolescente e a avaliação que fazem da mesma. Entre os nove participantes, três avaliaram a sua atual situação de vida como "muito insatisfatória ou insatisfatória", alegando a distância de quem gosta, a frustração de querer uma casa própria para morar e não conseguir, ou mesmo, a distância da rua, como justificativas para essa avaliação.

Dois jovens avaliaram como "regular", por entender que "tinha que melhorar muitas coisas" ou que "nem tudo é perfeito", seja pela falta de um emprego fixo e condições adequadas pra se manter, seja porque ainda usa drogas. Ao mesmo tempo, um dos jovens que avaliou a sua situação de vida como "regular", ao lado dos aspectos que ainda precisam ser melhorados, destacou as conquistas alcançadas com relação ao seu passado. Dentre estas, está o fato de que hoje aproveita as oportunidades de vida que lhe são dadas melhor que no passado, estando, inclusive, prestes a concluir um curso de padaria.

Quatro adolescentes avaliaram como "satisfatória ou muito satisfatória" a sua situação atual de vida. A principal justificativa refere-se à distância da rua e da droga e ao fato de estar fazendo algum curso ou participando de alguma oficina. Em comum, esses jovens têm o fato de estar morando em uma República ou sozinho. Um adolescente que ainda está na rua, avaliou a sua situação como "satisfatória", mas não descreveu nenhuma razão específica para tanto, somente o fato de estar vivo.

Entre os sete jovens que não estão mais na rua, verifica-se que esse é um evento relativamente recente. Para cinco jovens, tem até um ano; e para os outros dois, tem mais de um ano.

As principais justificativas ${ }^{4}$ dadas à questão "O que te levou a sair da rua" foram: 1) ter sido preso (duas respostas); 2) ter tido oportunidade de ir para a República e/ou ter um Bolsa 
Tabela 1

\begin{tabular}{lcll}
\multicolumn{5}{l}{ Situação atual de vida e avaliação da mesma para cada adolescente entrevistado } & \multicolumn{1}{c}{ Avaliação } \\
\hline Nome & Idade & \multicolumn{1}{c}{ Situação atual de vida } & Regular \\
Roberto & 19 & Rua & Satisfatória \\
Israul & 20 & Rua & Muito insatisfatória \\
Moisés & 19 & Presídio & Insatisfatória \\
Kleiton & 19 & Presídio & Regular \\
William & 18 & Casa de parentes/amigos & Muito insatisfatória \\
Márcio & 20 & Casa de parentes/amigos & Satisfatória \\
José & 20 & República & Muito satisfatória \\
Gustavo & 18 & República & Satisfatória \\
Leandro & 20 & Mora sozinho &
\end{tabular}

(duas respostas); 3) estar mais "maduro", "desejo de dar mais atenção para a família ou de constituir família" (três respostas); 4) desligamento do abrigo e/ou percepção de que a rua estava ruim (duas respostas); e 5) conselho de educadores (duas respostas). Compreende-se, assim, que os motivos são diversos e podem estar relacionados desde a "aspectos internos" (estar mais maduro, escutar conselhos, desejo de dar mais atenção para a família), até circunstâncias externas, como o fato de ser preso, ou de ser apresentado a outra alternativa viável de vida (a República, no caso) e conseguir uma Bolsa com a qual pode se manter. Nas falas de dois adolescentes, foi feita referência "nominal" a educadores que tiveram influência no processo de deixar a rua: "A Fernanda", que eu gosto demais, deu vários conselhos e ela gosta de mim e eu gosto dela".

\section{Percepção sobre a instituição e atendimento recebido}

A principal mediação para conhecer e frequentar a instituição de meio aberto, para cinco dos nove entrevistados, foram outros colegas e amigos da rua. Outros três jovens mencionaram a figura do educador social ou outro profissional da rede. Apenas um jovem disse ter buscado a instituição sozinho/espontaneamente.

A maioria dos participantes (sete) afirmou ter frequentado a instituição por um período de 1 a 3 anos, enquanto dois jovens afirmaram que permaneceram na instituição por mais de quatro anos. A principal justificativa para ter parado de acessar esse serviço de atendimento foi o fato de não ter mais idade (sete dos nove entrevistados). Apenas dois alegaram motivos diferentes: ter sido preso ou mudança de cidade.

Todos os participantes afirmaram, ainda, que enquanto frequentavam aquela instituição de meio aberto, acessavam também outros serviços da rede (Escola Aberta, o serviço de saúde para crianças em situação de rua e o albergue noturno, por exemplo). As principais respostas dadas à pergunta "por que você frequentava a instituição", estão sumarizadas na Tabela 2.

Verifica-se, assim, que para além das atividades relacionadas à higiene pessoal e alimentação dos adolescentes, está a

Tabela 2

Número total e percentagem de respostas sobre o porquê de frequentar a Instituição

\begin{tabular}{lc}
\hline \multicolumn{2}{c}{ Categorias } \\
\hline Atividades oferecidas (televisão, videogame, futebol, passeios, capela) \\
"Pra não ficar na rua usando droga" & $9(36)$ \\
Por causa da equipe & $4(16)$ \\
Higiene (banho, roupa limpa) & $3(12)$ \\
Alimentação & $3(12)$ \\
"Porque outros amigos iam também" & $3(12)$ \\
Dormir & $2(8)$ \\
Total & $1(4)$ \\
\hline
\end{tabular}

lembrança das diversas atividades oferecidas pela instituição (televisão, videogame, futebol, passeios, capela), como principal motivo dado pelos entrevistados para a frequência desse espaço. Merece destaque, ainda, a segunda resposta, a qual se refere à utilização da instituição como uma "estratégia de redução de danos", já que significa menos tempo na rua usando droga. Por fim, o reconhecimento dos adolescentes à equipe da instituição, expresso na resposta "por causa da equipe". Verifica-se, portanto, uma avaliação positiva desse espaço e das atividades ali desenvolvidas, conforme as frases abaixo evidenciam: “Alegria, diversão, gurizada, pessoas legais. Era um dia a menos se drogando." (Kleiton, 19 anos).

Coisas que eu não fazia quando era pequeno, eu fiz quando eu era maior, como jogar futebol, jogar vídeo-game, sair para passeios. Foi o que eu não fiz quando era pequeno. A minha infância eu não comecei de pequeno, a minha infância eu aprendi de maior, a minha infância... eu não soube aproveitar. Perdi muito cedo ela. (Israul, 20 anos).
Sobre o papel da instituição na vida dos jovens, as respostas podem ser sumarizadas em três categorias, conforme mostra a Tabela 3:

O maior percentual de respostas mencionadas pelos jovens faz referência à vivência e aprendizagem de valores, como é ilustrado nas frases a seguir:

"Me fez mudar em muitas coisas: parar de brigar, entender mais as pessoas, saber conversar e respeitar." (Roberto, 19 anos). "Uma força! Ajudou uma pessoa a erguer a cabeça; ver como ela não era um indigente, como ela tinha capacidade de... de erguer a cabeça dela e seguir em frente. Só isso!” (Israul, 20 anos).

Embora os jovens mencionem a aprendizagem de valores, fica claro que tal aprendizagem passou pela vivência concreta desses valores na instituição, através de relações marcadas pelo respeito mútuo entre os educadores e eles. Dessa forma, é frequente também nos relatos a lembrança de situações concretas que expressam companheirismo, a existência de um afeto positivo entre educando e educador, bem como a comparação 
Tabela 3

\begin{tabular}{lc} 
Número total e percentagem de respostas sobre o papel da instituição na vida dos participantes \\
\hline \multicolumn{1}{c}{ Categorias } & $\mathrm{n}(\%)$ \\
\hline Aprendizagem de Valores (respeito, cooperação, parar de brigar, educação, dignidade, & $7(58)$ \\
compreensão) & $3(25)$ \\
Vida, alegria, força & $2(17)$ \\
"Minha casa, minha família" & $12(100)$ \\
Total & 100 \\
\hline
\end{tabular}

de alguns educadores com a figura materna.

Minha segunda casa, como eu não tava (sic) em casa, foi onde eu comecei a ter mais oportunidades como se tivesse com a família. Aqui, sempre respeitei professores e monitores. Lembro muito dos torneios de futebol e um dia que sentei na sala da Angélica [diretora da instituição] e bati uma foto com a medalha que ganhei no torneio do Inter [o time foi vice-campeão e ele foi o artilheiro]. (William, 18 anos)

\section{Discussão}

Verifica-se que todos os jovens entrevistados possuíram um alto grau de vinculação com a instituição de meio aberto frequentada no ano de 2002. Estes jovens também possuíam uma vinculação forte com as demais instituições da rede de atendimento à infância/adolescência em situação de rua, uma vez que os dados revelam que todos frequentavam mais de um espaço ao mesmo tempo. Esse dado obviamente está relacionado com a forma como os participantes do presente estudo foram acessados, a partir do critério de conveniência.

Dada a alta vinculação com as instituições, é possível concluir que esses jovens (à época em que frequentavam o serviço de meio aberto) estariam naquela que Santana et al. (2010) nomeiam de terceira etapa da trajetória de vinculação institucional (TVI). Nesta fase, os adolescentes têm um grande contato com as instituições, inclusive organizando a sua rotina a partir das mesmas. No entanto, como problematizado pelas citadas autoras, essa vinculação não necessariamente implica num desejo efetivo de saída do espaço da rua.

No que se refere à vinculação com a instituição de meio aberto, especificamente, destaca-se a menção à aprendizagem de valores e a avaliação positiva das atividades e da equipe dessa instituição. Esses aspectos em conjunto foram mais mencionados do que o uso desse espaço como um lugar em que eles iam apenas para se alimentar e tomar banho. Ficou clara, portanto, a existência de laços afetivos positivos entre os adolescentes e educadores dessa (e de outras) instituição(ões). Para muitos desses jovens, foi na rua - através da mediação de algumas instituições - que eles tiveram oportunidades de vida, as quais não lhes foram dadas antes da ida para a rua.

Nesse sentido, conclui-se acerca da grande contradição, que o espaço da rua representa para muitas das crianças/ adolescentes que ali estão. Foi somente depois de sair de casa que alguns jovens disseram que começaram a "viver a sua infância", a ter oportunidades que antes não possuíam. Morais et al. (2010) discutem a chamada invisibilidade a que estão expostas crianças/adolescentes em suas comunidades e famílias de origem. A invisibilidade refere-se justamente ao fato de estarem à margem de políticas educacionais, de saúde, renda e lazer. Como se não bastasse a falta de acesso a serviços/direitos (de qualidade), a maioria dessas crianças/adolescentes estão também expostas a situações de risco ao seu desenvolvimento (tráfico, violência doméstica e comunitária, dentre outros). Ao deixarem a invisibilidade de suas comunidades e irem para os centros da cidade, essa população ganha visibilidade social e passa a ser público-alvo das políticas sociais, por mínimas que sejam. Paradoxalmente, para serem incluídas, elas precisaram ser primeiro excluídas, ter os seus direitos negados. Ademais, precisaram escolher talvez uma das mais radicais formas de inclusão, que é a situação de rua ${ }^{6}$.

A análise da modalidade de saída da rua, a partir dos três tipos descritos por Lucchini (2003), mostrou que cinco dos sete entrevistados a deixaram por "expulsão ou deslocamento forçado" (dois jovens que estavam presos), ou por "esgotamento de recursos" (três adolescentes). Nesse último caso, estão os jovens que referiram a saída da rua por terem completado 18 anos, por terem sido desligados do abrigo ou porque a situação na rua estava muito grave, devido ao uso abusivo de drogas. Apenas para os dois jovens que estavam morando na República pode-se pensar que a saída da rua esteve ligada a uma escolha e elaboração de um projeto concreto de vida, o que é definido por Lucchini (2003), como caracterizando uma "saída ativa". Ademais, nos dois depoimentos desses jovens, fica clara a relação intrínseca entre estar na República e ter uma Bolsa Jovem Adulto, para ajudar na sobrevivência, tal como ilustra o seguinte relato: "Aos poucos eu vou conseguindo alcançar minhas metas. A bolsa Jovem Adulto também me ajudou. Mostrou que é possível dominar as drogas, porque não gasto todos os R\$200,00 em droga." (Gustavo, 18 anos).

É interessante perceber que, entre os sete jovens que não estão mais na rua (excluindo os dois que estão presos), todos continuam a possuir algum grau de vinculação com a rede de atendimento. Dois deles moram na República e três moram com amigos/parentes ou sozinho. Nesse último caso, ressalta-se a baixa qualidade e a situação de pobreza em que ainda vivem, numa favela localizada nas proximidades da escola aberta, a qual é conhecida pelo tráfico. Três desses cinco jovens recebem a Bolsa Jovem Adulto. E todos avaliaram como essencial o recebimento da mesma como motivação para a saída da rua. Esses dados são corroborados pelos estudos de Pereira (2004) e Westphal (2001), nos quais os pesquisadores constataram que a realidade de vida pós-rua dos adolescentes (egressos de instituições que atendiam crianças em situação de rua) continuava a ser marcada por dificuldades.

A importância da vinculação entre educador e criança/ adolescente como parte fundamental do processo de trabalho foi bastante explicitada pelos participantes desse estudo. De 
fato, os educadores - em maior ou menor grau, dependendo das características e habilidades técnicas e pessoais de cada um - constituem uma parte muito importante da vida dessas crianças e adolescentes. Os educadores sociais e técnicos são fundamentais para permitir o acesso do jovem a formas diferentes de relacionamento, através das quais as crianças/adolescentes possam ser escutadas e respeitadas na sua subjetividade e forma de expressão. Além disso, os profissionais são, tanto figuras de autoridade quanto importantes fontes de afeto e carinho para esses jovens. Permitem acesso ao lúdico, à informação, aos cuidados básicos, partilham alegrias, mas também são os primeiros a confidenciar e fazer parte da dor dessas crianças e adolescentes. A proposta da Educação Social de Rua (Oliveira, 2004) e a chamada "Pedagogia da Presença" são bastante coerentes aos exemplos de educadores lembrados nas falas dos adolescentes. Trata-se de educadores que pautam o seu fazer diário, tanto em conhecimentos técnicos como em motivações existenciais, de estar com essas crianças/adolescentes, nos espaços onde elas estão.

Alguns autores como Milburn et al. (2005), elencaram algumas implicações para as políticas públicas, cuja aplicação é também bastante adequada à realidade brasileira e útil para pensar os dados obtidos nesse estudo. A primeira implicação é a de que se deve adotar serviços que sejam mais abrangentes (oportunidade de moradia, educacional e de trabalho) e com menor caráter compensatório (serviços de subsistência, por exemplo). Os autores defendem que estes últimos tipos de serviços (compensatórios), tendem a cronificar a situação de rua, fato que também é ressaltado por Santana, Doninnelli, Frosi e Koller (2005a, 2005b). A segunda implicação mencionada é a de que os serviços para as populações em situação de rua deveriam ser mais dispersos geograficamente, ao invés de estar limitado a áreas/regiões específicas das cidades. A terceira implicação refere-se à necessidade de que os profissionais que lidam com a população em situação de rua tenham treinamento em áreas específicas, tais como a de comportamentos de risco à saúde. Por fim, a quarta recomendação é a de que mais alternativas de stable housing sejam oferecidas aos jovens em situação de rua (a proposta da República em que vivem dois participantes desse estudo é um exemplo) e que os serviços atuassem de forma mais coordenada, capacitando os jovens a viverem nesses espaços, enquanto continuam construindo alternativas outras de vida.

$\mathrm{Na}$ direção dessas implicações práticas, já é realidade no contexto brasileiro uma proposta de regionalização do atendimento à situação de rua. Trata-se da experiência do Programa Ação-Rua, o qual é realidade na cidade de Porto Alegre, desde o ano de 2007. O referido Programa prevê a descentralização e a regionalização do atendimento às crianças/ adolescentes em situação de rua, de forma que se possa enfrentar a situação de rua preventivamente, tão logo a criança/adolescente esteja envolvido em atividades na rua, seja pela brincadeira ou trabalho. Além disso, o programa prevê o trabalho conjunto com as famílias das crianças/adolescentes e a articulação com todos os serviços da rede de assistência, como por exemplo, o Conselho Tutelar, sistema de saúde, escola, etc. (Finkler, 2011).

\section{Considerações finais}

Os dados do presente relato de pesquisa referem-se a um estudo qualitativo, realizado com nove adolescentes do sexo masculino que frequentaram uma instituição de meio aberto para crianças e adolescentes em situação de rua, na cidade de Porto Alegre, durante o ano de 2002. Os dados são ricos em conteúdo e atendem ao critério de saturação - repetição de dados - tradicionalmente destacado na literatura, como critério de validade para as pesquisas qualitativas.

As limitações do estudo dizem respeito à homogeneidade de perfil dos entrevistados (alta vinculação com a rua no passado e ainda - em maior ou menor nível - no presente), assim como ao critério de conveniência com o qual foram recrutados. Como sugestão para estudos futuros, sugere-se basicamente os pontos a seguir: 1) a inclusão de jovens do sexo feminino na amostra; 2) a inclusão de jovens que estão em "casa", que constituíram famílias, mas que estejam mais distantes da rua do que os jovens participantes do presente estudo; e, por fim, 3) a inclusão de jovens que acessaram o respectivo serviço de meio aberto poucas vezes no ano de 2002 e que tiveram um menor grau de vinculação com a rua se comparado aos participantes desse estudo.

Finalmente, para além das limitações do presente estudo, é possível afirmar que os dados aqui analisados corroboram a importância de se escutar crianças/adolescentes que um dia estiveram em situação de rua e foram atendidos nesses serviços. Em última instância, acredita-se que um olhar retrospectivo pode ser uma ótima oportunidade para se avaliar como os serviços se configuram na atualidade.

\section{Referências}

Bardin, L. (1979). Análise de conteúdo (L. A. Reto \& A. Pinheiro, Trads.). São Paulo: Edições 70/ Martins Fontes. (Obra original publicada em 1977)

Brito, R., \& Koller, S. H. (1999). Desenvolvimento humano e redes de apoio social e afetivo. In A. M. Carvalho (Org.), O mundo social da criança: natureza e cultura em ação (pp. 115-129). São Paulo: Casa do Psicólogo.

Finkler, L. (2011). Avaliação de um programa social para crianças e adolescentes em situação de rua e suas famílias. (Tese de Doutorado). Universidade Federal do Rio Grande do Sul, Porto Alegre.

Guareschi, N. M. F., Reis, C. D., Huning, S. M., \& Bertuzzi, L. D. (2007) Intervenção na condição de vulnerabilidade social: um estudo sobre a produção de sentidos com adolescentes do programa do trabalho educativo. Estudos e Pesquisas em Psicologia, 7(1), 17-27.

Harris, M. S., Johnson, K., Young, L., \& Edwards, J. (2011). Community reinsertion success of street children programs in Brazil and Peru. Children and Youth Services Review, 33, 723-731.

Lucchini, R. (2003). A criança em situação de rua: uma realidade complexa. In I. Rizzini (Org.), Vida nas ruas: crianças e adolescentes nas ruas: trajetórias inevitáveis? (pp. 45-86). Rio de Janeiro/São Paulo: PUC-Rio/Loyola.

Malvasi, P. A. (2008). ONGs, vulnerabilidade juvenil e reconhecimento cultural: eficácia simbólica e dilemas. Interface Comunicação, Saúde e Educação, 12(26), 605-617.

Milburn, N. G., Rosenthal, D., \& Rotheram-Borus, M. J. (2005). Needed: services research with homeless young people. Journal of Health \& Social Policy, 20(3), $1-9$

Morais, N. A. (2009). Trajetórias de vida de crianças e adolescentes em situação de vulnerabilidade social: entre o risco e a proteção. (Tese de Doutorado). 
Universidade Federal do Rio Grande do Sul, Porto Alegre. Recuperado de http://hdl.handle.net/10183/16660 (000704367)

Morais, N. A., Koller, S. H., \& Raffaelli, M. (2012). Rede de apoio, eventos estressores e mau ajustamento na vida de crianças e adolescentes em situação de vulnerabilidade social. Universitas Psychologica, 11(3), 779-791.

Morais, N. A., Neiva-Silva, L., \& Koller, S. H. (2010). Endereço desconhecido: crianças e adolescentes em situação de rua. São Paulo: Casa do Psicólogo.

Oliveira, W. F. (2004). Educação social de rua. Porto Alegre, RS: Artmed.

Pereira, A. (2004). História oral de egresso e a função social de instituição de atendimento a criança e ao adolescente "em situação de rua". Trabalho apresentado na VII Semana de Mobilização Científica, Universidade Católica de Salvador.

Raffaelli, M. (1999). Street youth in Latin America: a developmental review. Interamerican Journal of Psychology, 32, 7-28.

Raffaelli, M., Koller, S. H., \& Morais, N. A. (2007). Assessing the development of Brazilian street youth. Vulnerable Children and Youth Studies, 2, 154-164.

Ramos, N. V. (2006). Escola e rua: jovens egressos recontam suas histórias. Santa Maria: Pallotti.

Santana, J. P., Doninelli, T. M., \& Koller, S. H. (2010). Trajetória de vinculação institucional de crianças e adolescentes em situação de rua. In N. A. de Morais, L. Neiva-Silva \& S. H. Koller (Orgs.), Endereço Desconhecido: crianças e adolescentes em situação de rua (pp. 405-420). São Paulo: Casa do Psicólogo.

Santana, J. P., Doninelli, T. M., Frosi, R. V., \& Koller, S. H. (2004). Instituições de atendimento a crianças e adolescentes em situação de rua. Psicologia e Sociedade, 16(2), 59-70.

Santana, J. P., Doninelli, T. M., Frosi, R. V., \& Koller, S. H. (2005a). É fácil tirar a criança da rua. O difícil é tirar a rua da criança. Psicologia em Estudo, 10, 165-174.

Santana, J. P., Doninelli, T. M., Frosi, R. V., \& Koller, S. H. (2005b). Os adolescentes em situação de rua e as instituições de atendimento: utilizações e reconhecimento de objetivos. Psicologia: Reflexão e Crítica, 18, 134-142.

Siqueira, A. C., Betts, M. K., \& Dell'Aglio, D. D. (2006). Redes de apoio social e afetivo de adolescentes institucionalizados. Interamerican Journal Psychology, 40(2), 149-158.

Souza, M. G., Reis, M. L. A., Corrêa, N. M. B., \& Giugliani, S. (2010). InterRua: experiência de Porto Alegre. In N. A. de Morais, L. Neiva-Silva \& S. H. Koller (Orgs.), Endereço Desconhecido: crianças e adolescentes em situação de rua (pp. 465-498). São Paulo: Casa do Psicólogo.

Westphal, R. B. (2001). Meninos de rua: investigando o estigma da insanidade. Dez histórias de respostas positivas a uma socialização de risco. (Tese de Doutorado). Universidade Federal do Rio de Janeiro, Rio de Janeiro

1. Por instituição de meio aberto entende-se aqui um serviço diurno de atendimento para crianças/adolescentes e situação de rua, na qual as mesmas podem entrar e sair com uma flexibilidade maior de horários. Trata-se de um espaço onde as crianças/adolescentes passam o dia, ou ao menos um dos turnos e que não se configura como um acolhimento institucional (abrigo). Também não é o espaço onde as crianças pernoitam, mas onde podem atender suas demandas de alimentação, higiene e realizar algumas atividades lúdico e pedagógicas, enquanto estão na rua.

2. Para uma melhor descrição desses serviços, ver Souza, Reis, Corrêa e Giugliani (2010), as quais descreveram os serviços que compõem a rede de atendimento a crianças/adolescentes na cidade de Porto Alegre, RS.

3. Tomou-se por base o ano de 2002, pois este é o ano a partir do qual a instituição possuía registro de lista de frequência de todos os meses do ano.

4. A questão comportava mais de uma resposta por sujeito.

5. Nome fictício da técnica/educadora, a fim de garantir sigilo da identidade.

6. Outras formas de inclusão "perversa" que poderíamos nomear são o ato infracional, o suicídio e a dependência química, por exemplo.

Normanda Araujo de Morais, doutora em Psicologia pela Universidade Federal do Rio Grande do Sul (UFRGS), é Professora do Programa de Pós-Graduação em Psicologia da Universidade de Fortaleza (UNIFOR). Endereço para correspondência: Universidade de Fortaleza, Programa de Pós-Graduação em Psicologia. Av. Washington Soares, 1321, Bloco N - Sala 13, Edson Queiroz, CEP: 60811-905 - Fortaleza, CE. E-mail: normandaaraujo@gmail.com

Silvia Helena Koller, doutora em educação pela Pontifícia Universidade Católica do Rio Grande do Sul (PUCRS), é Professora da Universidade Federal do Rio Grande do Sul (UFRGS). E-mail: silvia.koller@ pq.cnpq.br 